\title{
Relative Importance and Knowledge Distribution of Medicinal Plants in a Kichwa Community in the Ecuadorian Amazon
}

\author{
Brian J. Doyle ${ }^{1^{*}}$, Caroline M. Asiala ${ }^{1}$, and Diana M. Fernández ${ }^{2}$ \\ ${ }^{1}$ Department of Biology and Department of Biochemistry, Alma College, Alma, MI, USA. ${ }^{2}$ National Institute of Biodiversity, \\ National Herbarium of Ecuador, Quito, Ecuador. \\ *doylebj@alma.edu
}

\begin{abstract}
Traditional knowledge, such as knowledge of the use of plants as medicine, influences how indigenous people manage forest resources. Gender and age-associated differences in traditional knowledge may impact forest resource management because of the traditional division of labor. We interviewed 18 men and 18 women between 9 and 74 years old in San José de Payamino, an indigenous community of the Kichwa ethnicity in the Ecuadorian Amazon, to determine if there are gender or age-associated differences in medicinal plant knowledge among the Payamino people and to identify the most important species from a sample of medicinal plants. Individuals were interviewed using a tablet that displayed images of 34 plants, which had been cited by traditional healers in the community. Quantitative analysis provided insight into the relative importance of plants in the sample as well as the distribution of medicinal plant knowledge among members of the community. The most important plants were Tradescantia zanonia and Monolena primuliflora. These plants should be considered candidates for further investigation. There was a positive correlation between age and knowledge of medicinal plants, but no significant difference between genders. Our results suggest that an interview method that relies on digital images can reveal differences in the importance of medicinal plants as well as provide insight into the distribution of traditional medical knowledge. While men and women are likely to manage forest resources similarly, younger members of the community may not have the same regard for forest resources as their elder counterparts.
\end{abstract}

Received August 24, 2016

OPEN ひACCESS

Accepted November 16, 2016

DOI 10.14237/ebl.8.1.2017.777

Keyword Traditional medicine, Ethnobotany, Quichua, Runa, Payamino

Copyright (c) 2017 by the author(s); licensee Society of Ethnobiology. This is an open-access article distributed under the terms of the Creative Commons Attribution-NonCommercial 4.0 International Public License (https://creativecommons.org/licenses/by-nc/4.0), which permits non-commercial use, distribution, and reproduction in any medium, provided the original author and source are credited.

\section{Introduction}

San José de Payamino is a community of Quijos Kichwa-speaking people located in the Ecuadorian Amazon. The Payamino people are revered by neighboring communities for their adherence to a relatively traditional lifestyle, which includes the use of plants as medicine (Irvine 1987). The earliest account of Payamino ethnobotany included notes on plant use and a list of plants collected in the Payamino territory (Irvine 1987). Irvine delineated the role of Payamino shamans as individuals trained in the use of medicinal plants, and who have more knowledge of, and experience with, medicinal plants than other members of the community. According to Irvine, most members of the community have some basic medical knowledge, and she hypothesized that because of the traditional division of labor, gender and age-associated differences in plant knowledge may have an impact on the management of forests. Research in the area of social ecology supports the idea that traditional knowledge, such as knowledge of the use of plants as medicine, impacts how indigenous people manage forest resources (Berkes et al. 2000; Colding and Folke 2001). The objective of our study was to determine if, in fact, there are any gender or age-associated differences in medicinal plant knowledge among the Payamino people. In addition, we aimed to determine the medicinal plants that are most important to the Payamino people to more fully characterize Payamino ethnomedicine and to identify species that might be candidates for further ethnobotanical, phytochemical, and pharmacological investigation. 


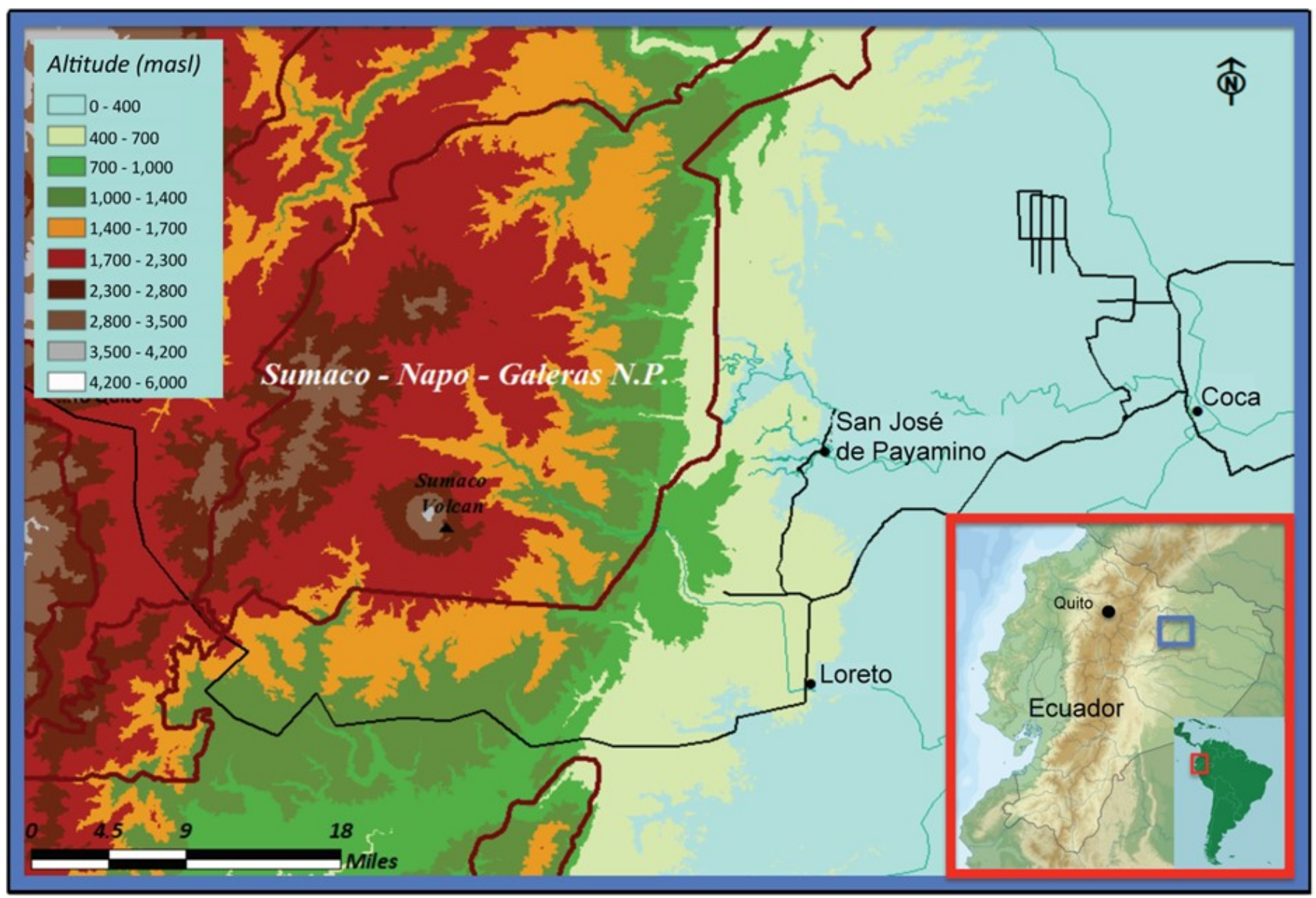

Figure 1 Location of San José de Payamino relative to the nearest towns of Coca and Loreto and the Sumaco - Napo - Galeras National Park (Timburi Cocha 2015).

Recently, the most knowledgeable members of the community, the traditional healers (shamans and curanderos), were interviewed using a forest walk, or walk-in-the-woods, method (Doyle et al. 2014). While an intensive forest walk interview may be appropriate for very knowledgeable participants, this approach is not practical for broader participation. Forest walks are typically very time consuming and labor intensive, particularly when conducted in challenging settings, such as in the Amazon. As an alternative approach, structured interviews that rely on plant images rather than fortuitously encountering plants in the forest allows for more efficient and consistent data collection (Thomas et al. 2007). Thomas et al. (2007) highlighted the advantages of using photographs of plants rather than voucher specimens or freshly collected plant material in ethnobotanical interviews. Participants recognized $92-96 \%$ of photographs of plants that they had indicated and named during prior forest walk interviews but only $68-86 \%$ of voucher specimens. Therefore, using images of plants proved to be an effective interview method.

In the present study, we adapted the approach used by Whitecloud et al. (2014) where participants were presented digital photographs of plants on an electronic tablet. The presentation of digital images has several advantages over printed images or voucher specimens. For example, the tablet provides a similar visual experience under most conditions. Since most interviews are conducted in the homes of informants, which tend to be somewhat dark, the backlit screen, adjustable brightness, and zoom function of the tablet enable scrutiny of morphological characteristics under these conditions. Furthermore, tablets allow one to take photographs and record audio and video during the interview process, and in fact, images taken in situ are immediately available for use in ex situ interviews. Lastly, data can be entered directly into a spreadsheet 
or text document on the tablet, which allows for organization, analysis and digital archival of field notes at the study site. Electronic tablets can be encased in a waterproof cover that does not interfere with the visibility or the interactivity of the screen. Only one informant, a male 79 years of age, was excluded due to difficulty seeing the images.

\section{Methods}

Description of the Study Area

San José de Payamino is located roughly $45 \mathrm{~km}$ west of Coca (Puerto Francisco de Orellana) in Loreto Canton, Orellana Province (Figure 1). The community claims ownership of a 16,800 ha territory and is comprised of between 270 and 300 individuals in approximately 60 households (Oldekop et al. 2012). The Payamino territory lies within the buffer zone of the Sumaco Napo-Galeras National Park, which was designated in 2000 as a World Biosphere Reserve by UNESCO. The study area is predominantly lowland tropical moist forest (elevation is $300-400 \mathrm{~m}$ AMSL (above mean sea level)) that is transitional between the Andes foothills and the lower elevation region inhabited by Kichwas along the Napo River to the east. The high biodiversity of the region is attributed to this transitional geography (Arias et al. 2012; Innerhofer and Bernhardt 2011). The Payamino people practice subsistence farming, hunting, and fishing as well as small-scale farming of cash crops such as corn, rice, and cacao. Anthropological and socioecological studies have been conducted in Payamino first by Irvine (1987), who conducted an extensive survey of the local flora, and more recently by Oldekop et al. (2012a, b, 2013).

\section{Interview Method}

Authorization to conduct our study was obtained from the Institutional Review Board of Alma College, and all necessary research permits and authorizations were obtained from the community of San José de Payamino and from the Ministry of Environment of Ecuador under the auspices of the National Museum of Natural Sciences of Ecuador. Interviews were conducted from May-June, 2014. Participants were sought with the assistance of a community liaison, and all participants gave their informed consent. A parent's signature was obtained for child participants. Interviews were conducted in Spanish, but in a few cases the community liaison translated between Spanish and Kichwa. The interviews were conducted individually whenever possible, although onlookers and secondary participants were sometimes present. The average duration of the interviews was approximately one hour.

The interviews were semi-structured and based on the methodology described by Alexiades (1996) as a plant interview or checklist interview with the exception that digital images were used as visual aids rather than live, freshly-collected, or dried plant material. Vernacular names were not presented with the images because these names tend to correspond to the medicinal use of the plant (e.g. kiru jambi yura means tooth medicine stem). Each participant was shown a series of plant images on an iPad mini 2 with a 7.9 in. Retina display (Apple, Cupertino, CA). The name of the plant, the medicinal use, the preparation, and administration were recorded for each plant queried. The digital images, which were created by the authors in Payamino, represented 34 species that were cited by eight Payamino healers (men and women) during forest walk interviews from 2012-2014. Voucher specimens were collected at the time the photographs were taken and were identified by staff at the National Herbarium in Quito (QCNE) where the specimens are deposited. The Catalog of the Vascular Plants of Ecuador (Jorgensen and León-Yánez 1999) was used to facilitate identification, and the currently accepted scientific name of each plant was determined by consulting The Plant List (2013). The 34 plants were selected from 60 species that had been identified as part of our ongoing ethnobotanical survey in Payamino (Doyle et al. 2014). They were cited by more than one of the traditional healers that had previously participated in forest walk interviews. Thus, plants that are more likely to be integral to the Payamino ethnomedical pharmacopoeia were chosen rather than plants that might be particular to an informant (Giovannini 2015; Vandebroek 2010).

\section{Quantitative Analysis}

Several indices were utilized to identify plants from among the 34 plants in our sample that are most important in the traditional medicine of the Payamino people. The first was the Relative Frequency of Citations (RFC), which is simply the fraction of informants that recognized a given plant as medicinal (Tardío and Pardo-de-Santayana 2008). RFC was calculated as follows:

$R F C=N / N_{i}$

where $N$ is the number of informants who cited any medicinal use for the plant and $N_{i}$ is the total number 
of informants (36). An RFC of one would indicate that all informants recognized the plant as medicinal and cited at least one use, whereas, an RFC of zero would indicate that no informants cited a medicinal use for the plant.

The Use Value introduced by Philips and Gentry (1993a, b) and simplified by Rossato et al. (1999) was calculated as a measure of the diversity of medicinal uses cited for a given species. UV is expressed as:

$U V=N_{r} / N_{i}$

where $N_{r}$ is the total number of medicinal use citations in all therapeutic categories for all informants, and $N_{i}$ is the total number of informants (36). Use citations were divided into ten therapeutic categories, such that the theoretical maximum use value for a species is ten. This would require that all 36 informants cite a medicinal use in each of the ten therapeutic categories for a given species.

Fidelity Level (FL), as described by Friedman et al. (1986 cited in Andrade-Cetto and Heinrich 2011), is used to determine the level of agreement among informants on a plant's medicinal use. We calculated FL as follows:

$F L=N_{p} / N$

where $N_{p}$ is the number of informants who reported a particular use for the species, and $N$ is the number of informants who cited any medicinal use for the species. Our FL differs from that used by Friedman et al. (1986) in that we presented the informants with the plant images and asked them to cite uses rather than asking informants to cite plants that have a particular use. An FL of one would indicate that all informants that recognized the plant as medicinal cited the same medicinal use while an FL approaching zero would indicate that each informant that recognized the plant as medicinal cited a different use. Although an FL may be calculated for each use cited for a particular species, only the medicinal use for which the FL was highest is reported here.

The Index of Agreement on Remedies (IAR) is used to quantify the importance of plants for which there is consensus on more than one medicinal use (Mootoosamy and Mahomoodally 2014; Mutheeswaran et al. 2011; Vandebroek 2010). A variation on Trotter and Logan's (1986) Informant Agreement Ratio, the IAR considers all cited usage categories. Thus, a plant with a high number of citations in more than one use category may rank higher than plants with more citations in any single category. IAR was calculated as follows:

$L A R=\left(N_{r}-N_{a}\right) /\left(N_{r}-1\right)$

where $N_{r}$ is the total number of use citations for a given species across all therapeutic categories and $N_{a}$ is the number of cited therapeutic categories.

The last index is a sum of the IAR and RFC values and has a maximal value of two. It is intended to overcome the inherent limitations of each measure (Hoffman and Gallaher 2007; Kvist et al. 1995). For example, if few informants recognize a plant image, but all those who do recognize the plant agree on its medicinal use, IAR will be very high while the RFC will be low. Alternatively, many informants might recognize a plant as medicinal, which would result in a high RFC, but if each informant cites a different medicinal use, then IAR would be low. Neither index on its own gives a sense of the importance of the plant. We decided that combining these two values gave the best measure of relative importance for our study because it takes into account the percentage of informants who recognized a given plant as medicinal as well as the level of agreement among informants on the medicinal uses of the plant, realizing that the most important plants may have more than one agreed upon use.

\section{Statistical Analysis}

All statistical analyses were performed with IBM SPSS Statistics Version 20 software. A p-value of less than 0.05 was considered to be statistically significant. Spearman's rank-order correlation analysis was done to determine if there was a correlation between age and the number of plants recognized as medicinal. We conducted Fisher's Exact Test to identify differences in RFC and FL of plant species among age and gender groups.

\section{Results}

Thirty-six interviews were conducted with an equal number of male and female informants between 9 and 74 years old. Experts, such as individuals that would be considered shamans or curanderos, and non-experts were represented. The mean age of informants was 34 years, and the mean age of females (40 years) was 11 years \pm 6 (SE) older than the mean age of males. Use citations were grouped into ten categories as listed in Table 1 to facilitate quantitative analysis. 
Table 1 Medicinal use citations were organized into ten use categories.

\begin{tabular}{ll}
\hline Use Category & Description \\
\hline A-injuries & Bites, stings, cuts, burns, etc. \\
B-gastrointestinal & Stomach aches, diarrhea, etc. \\
C-respiratory & Fever, cold, cough, sore throat, etc. \\
D-mal viento & Mal viento or mal aire refers vaguely to a bad feeling or ill health. Some participants associated it \\
& with vomiting and/or having drank alcohol the night before. \\
E-skin infections & Includes rashes and granos, a word used to describe spots, marks, or lesions on the skin \\
F-aches/pains & Generalized pain, muscular pain, back/leg aches, headaches, toothaches, etc. \\
G-tumores & Swollen pustule in the abdomen or other part of the body. \\
H-women's health & Menstrual cramps, lactation-inducing, birth control, and other conditions specific to women \\
I-eye infections & Any condition described as making eyes itch, red, etc. \\
O-other & Insomnia, sleepiness, dizziness, laziness or misbehavior in children, fussiness in babies, and other \\
& conditions rarely mentioned during the interviews \\
\hline
\end{tabular}

The most often cited use category was aches and pains (120 citations) followed by injuries including bites and stings (107), respiratory ailments (74), gastrointestinal complaints (58), skin infections (42), tumores (40), mal viento (34), “other" (25), women's health (25), and eye infections (11). The most frequently used plant part was the leaves (19 plants) followed by stems (6), latex (4), bark (3) and flowers (2). Relative importance indices were calculated for each plant based on the responses of the participants (Table 2). Two of these indices, RFC and IAR, were summed resulting in a numerical value that was used to rank the plants in order of importance. By this measure the five most important plants in the sample are Urera baccifera, Tradescantia zanonia, Brunfelsia grandiflora, Croton lechleri, and Monolena primuliflora.

We found that there was a positive relationship between age and medicinal plant knowledge as measured by the number of plants recognized as medicinal (Figure 2), though there was no significant difference in medicinal plant knowledge between male and female informants. Of the 34 plant species presented, both male and female informants recognized 14 plants on average. In order to identify any plants that might differ in importance depending on the age of the informant, informants were divided into three age groups $(\leq 20,21-39$, $\geq 40)$. Recognition of Abuta imene as a medicinally useful plant (RFC) was significantly higher in the oldest age group than the youngest age group $(p<0.01)$. Agreement on the medicinal use of B. grandiflora (FL) was higher in the older age group than in the middle age group. Participants in the oldest age group mentioned $B$. grandiflora significantly more for treating colds than the other age groups $(\mathrm{p}<0.05)$. In general, there was more agreement on use (FL or IAR) among informants in the older age groups than the younger age groups. No species emerged as significantly different in importance between gender groups.

\section{Discussion}

An interview method based on presentation of digital images on an electronic tablet enabled inclusion of a relatively large number of participants representing both genders and a wide range of ages. We determined that there was a positive correlation between age and knowledge of medicinal plants, but that there was no difference in knowledge between genders. In addition, the relative importance of species included in the study was determined through quantitative analysis of informant responses. Interestingly, a plant that is used for wound healing, and that has yet to be extensively investigated, emerged as one of the most important plants.

The plants that were most important to the Payamino people among the 34 in our sample were identified through calculation of RFC, FL, UV, and IAR indices. Because only a subset of medicinal plants used by the Payamino people are represented in our sample, it was not possible to calculate some relative importance indices such as informant consensus (Trotter and Logan 1986), which is a measure of 


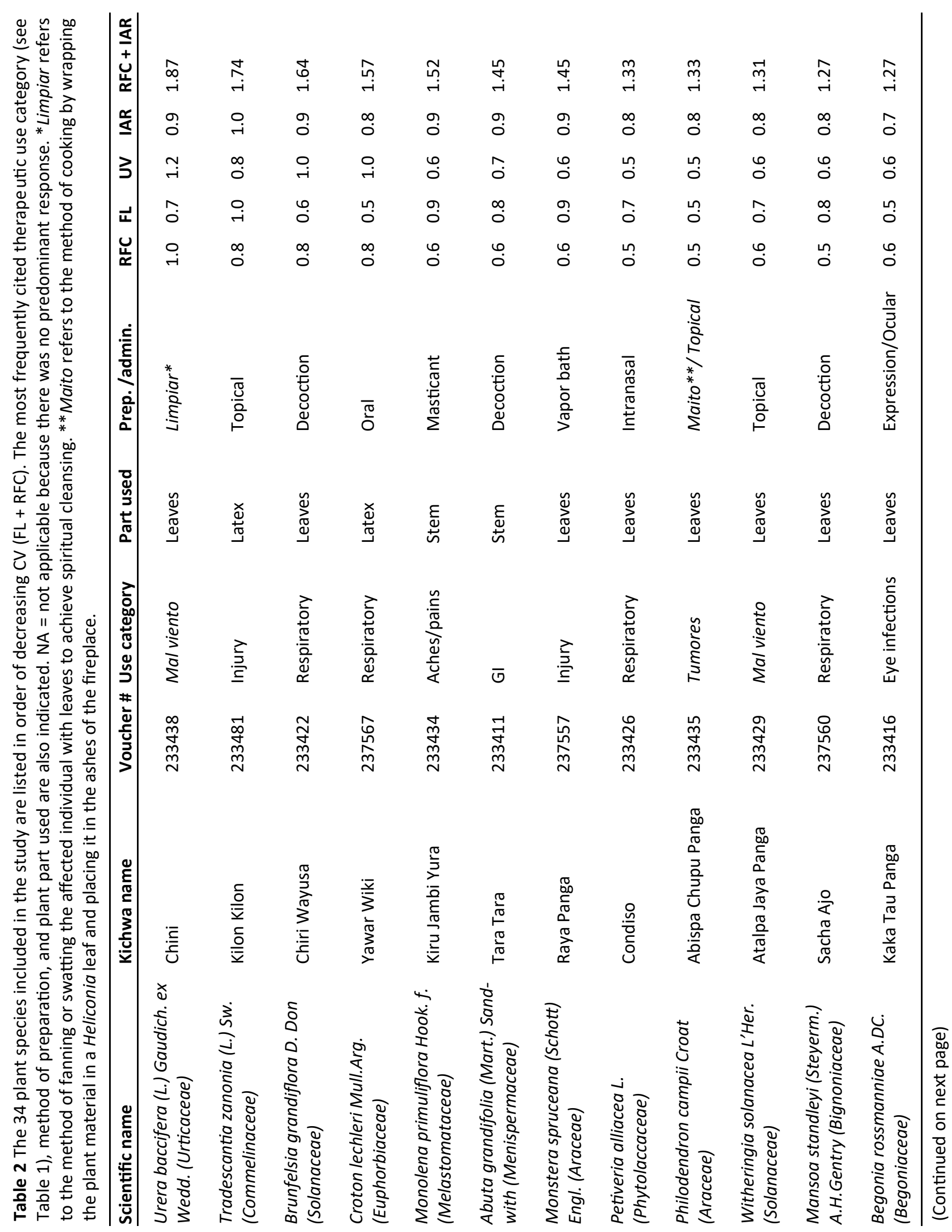




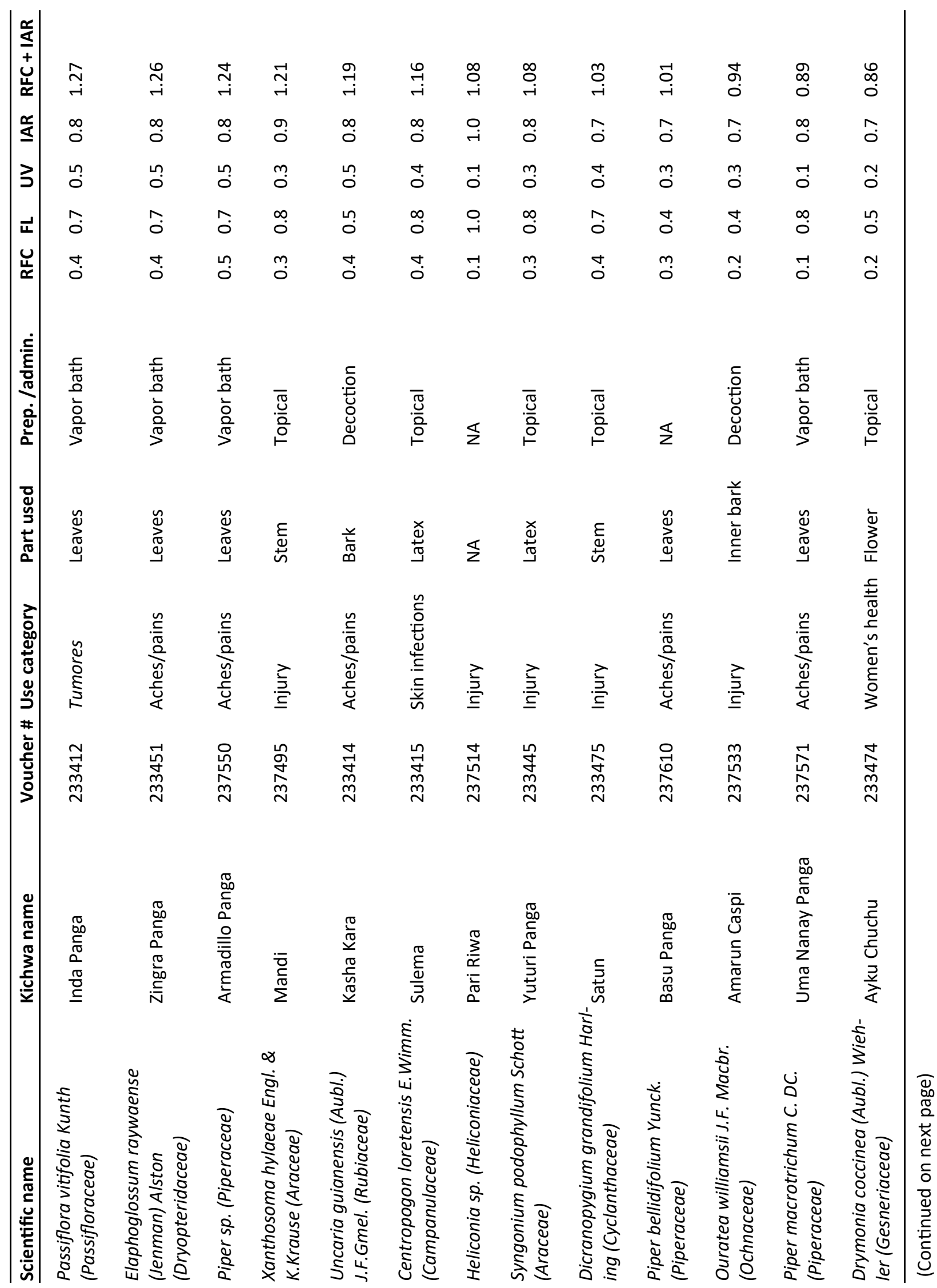




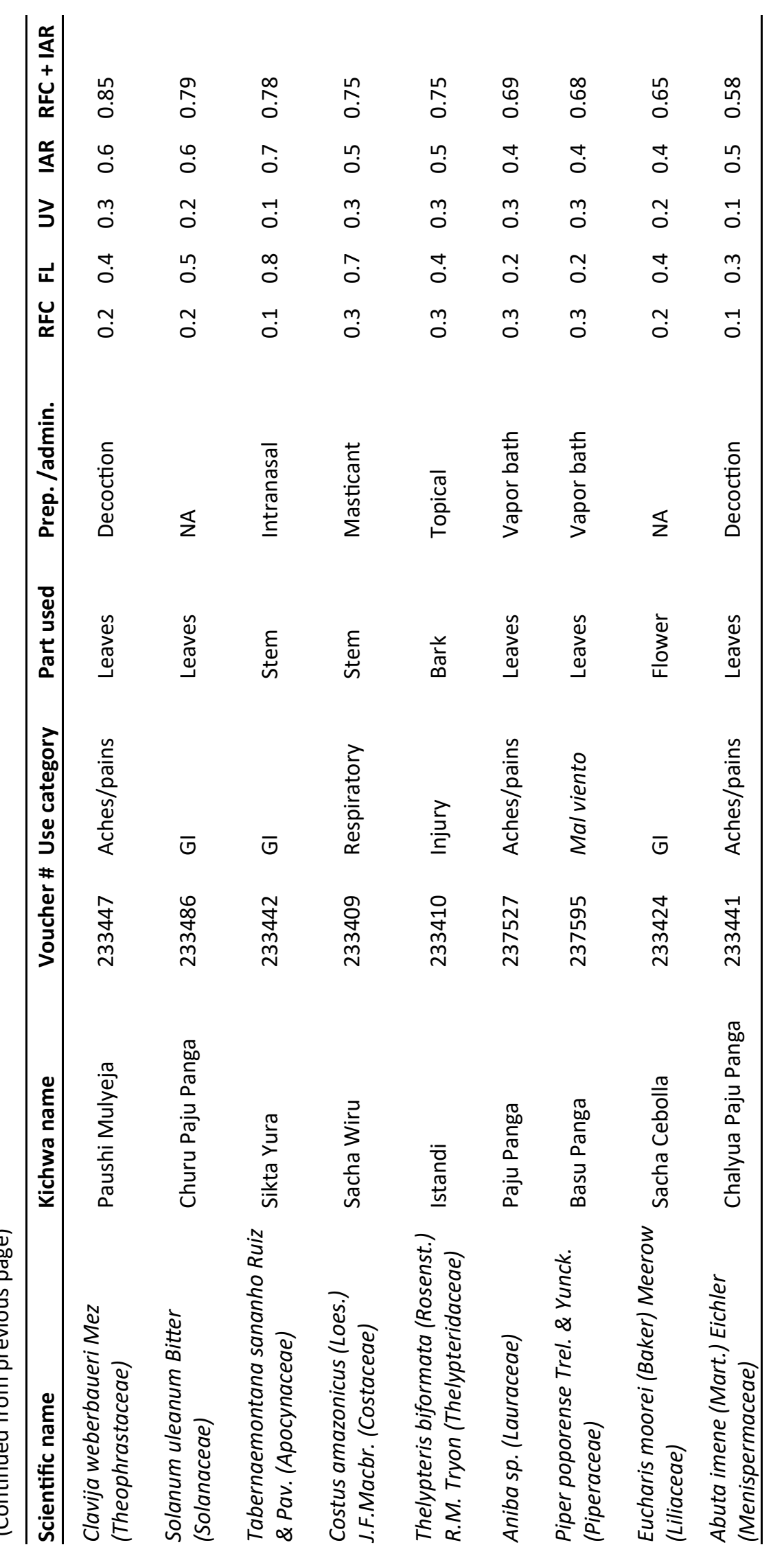


agreement on which plants are most important for a particular usage category. It is possible that the most important plant for a given category is not included among our 34 plants. In the future, however, the current study could be conducted with different plant species such that the data set covered a larger portion of the Payamino pharmacopoeia. Our approach could also be augmented by incorporating additional methods such as freelisting to gather data on plants not included in the sample.

There were no plants in our sample that were not recognized as medicinal by at least three informants, which suggests that the images were not seriously flawed in any way that would render the plants unrecognizable. Nonetheless, it is a concern that the RFC might be to some extent a measure of the quality of the image rather than the value or importance of the plant. Similarly, FL and IAR are imperfect measures of importance because they depend on the assignment of use citations to various therapeutic categories (Friedman et al. 1986). Although several use categories are commonly used, other use categories may be culture-specific, and categorization of each use citation may not always obvious (Heinrich et al. 1998). The number and inclusiveness of categories may also impact importance indices. When using FL as a measure of importance, an assumption is made that a plant with a single use is more important than a plant that is used for different purposes by different users, so the level of agreement on the most common use determines the plant's importance. In contrast, IAR takes into account the contribution of multiple different uses to a plant's relative importance. A species may have a higher IAR index than FL index if there is a high level of agreement on the plant's use in more than one category. The IAR would be lower than the FL if there is a high level of agreement in one category, but a low number of citations in multiple other categories. We reasoned that the sum of the IAR and RFC would best represent the importance of each medicinal plant since this would account for the percentage of informants who recognize the plant as medicinal (RFC) as well as the level of agreement among informants as to the use or uses of the plant (IAR).

The five plants with the highest IAR + RFC values were $U$. baccifera, T. zanonia, B. grandiflora, $C$. lechleri, and M. primuliflora. Tradescantia zanonia and $M$.

Figure 2 Location of San José de Payamino relative to the nearest towns of Coca and Loreto and the Sumaco - Napo - Galeras National Park (Timburi Cocha 2015).

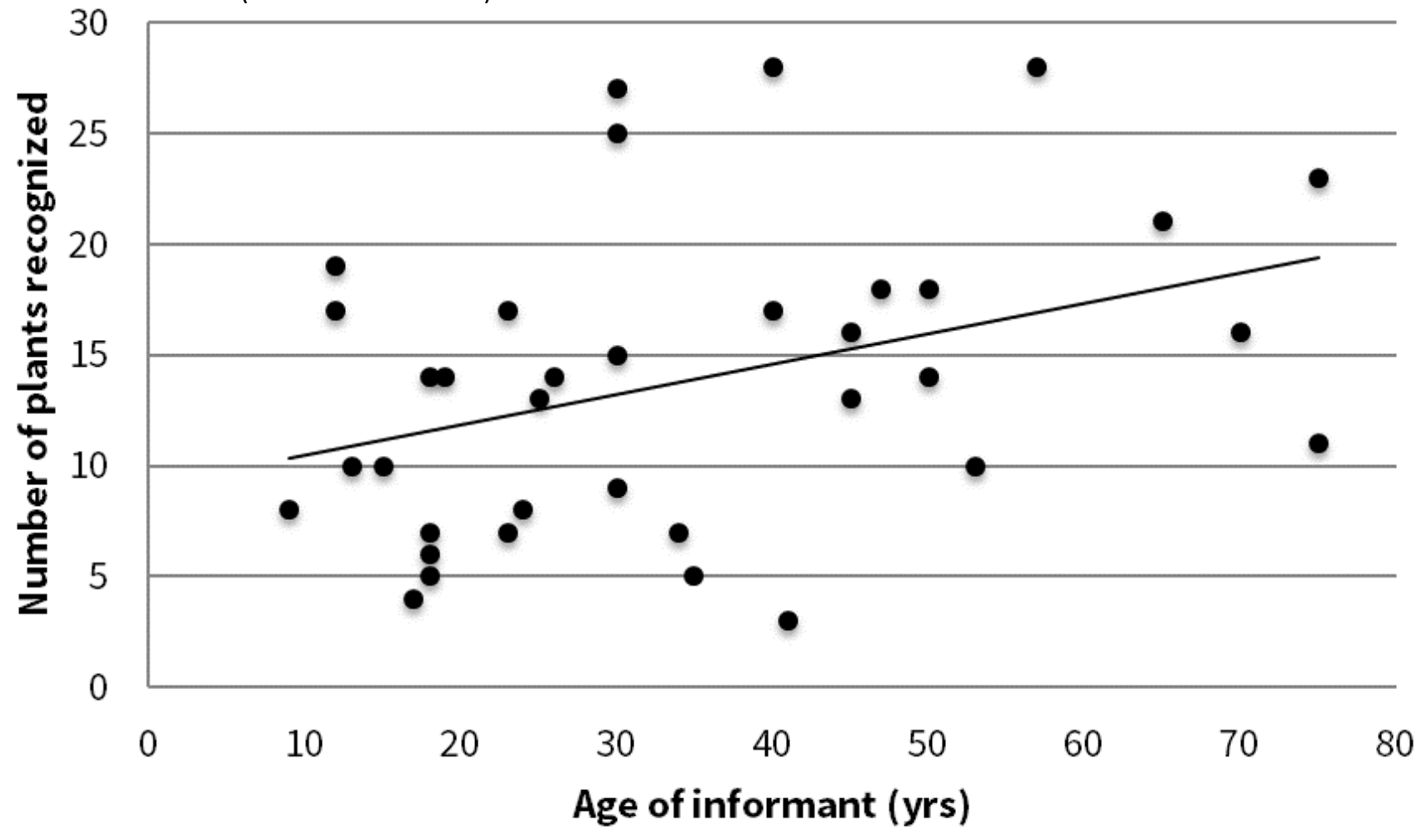


primuliflora have not been widely reported in the ethnomedical literature, so their relative importance in Payamino ethnomedicine might not be expected. Urera baccifera, B. grandiflora, and C. lechleri, however, are well-known medicinal plants that are commonly used throughout the region. Urera baccifera is a stinging nettle that is used to treat aches and pains due to sore muscles, arthritis, stings and bites (Bennett et al. 2002; Davis and Yost 1983; Giovannini 2015; Schultes and Raffauf 1990). The affected region of the body is placed into contact with the plant's urticating hairs, usually by tapping with the stem and leaves followed by massaging the affected area. Urera bacifera is also used in ritual cleansing, and it is common to punish children with a swat of the stem. In the nearby town of Loreto, $U$. baccifera was the third most frequent response when participants were asked which plant they harvested most recently for medicinal use (Innerhofer and Bernhardt 2011).

The Payamino people use the viscous sap of $T$. zanonia as a liquid bandage to treat injuries ranging from small cuts to large open wounds. Although the plant does appear in the ethnomedical literature, its use as a cicatrizant is not widely reported. A hydroalcoholic extract of the sap of $T$. zanonia was demonstrated to be more effective at promoting wound healing in rats than the topical antibiotic and steroidal anti-inflammatory drug Lamoderm (Licuy-Mamallacta 2013). The latex of T. zanonia is applied topically by the Teribes of Bocas del Toro, Panama for hemorrhage, but not for wounds (Gupta et al. 2005). The Quechua people of the Chazuta Valley in Peru chew the aerial parts or boil them in water and drink the extract for cough suppression, referring to it as pampa llullu (Sanz-Biset et al. 2009). In the southern Ecuadorian provinces of Loja and Zamora, the fresh stem of T. zanonia is prepared as an infusion and drunk for fevers (Tene et al. 2007). Although T. zanonia has been the focus of cytological studies, primarily on the effects of radiation on chromosomal aberrations, few phytochemical studies have been conducted on this species (Anderson and Sax 1936; Chiriboga 1995; Savage and Pritchard 1969). A phytochemical screening of $T$. zanonia revealed the presence of alkaloids, sterols, and saponins, though the identities of these chemical constituents and their contribution to the cicatrizant activity of the plant are not known (Chiriboga 1995).

In Payamino the leaves of B. grandiflora are boiled in water and drunk or administered as a vapor bath for fevers and body aches. The Kichwa word chiri in the name chiri wayusa means "cold" and refers to the chill felt upon ingestion of the plant. The use of stem and root bark is common in other parts of the Northwest Amazon where it is one of the most important remedies for rheumatism (Plowman 1977).

The red latex of C. lechleri, for which this tree is named dragon's blood or sangre de drago, is applied topically for cuts and wounds. In addition, a few drops of the latex are dissolved in water and taken for diarrhea. This traditional use as an anti-diarrheal has led to the development of the FDA-approved drug crofelemer, a crude botanical drug comprised of the latex of C. lechleri. Crofelemer is indicated specifically for diarrhea associated with antiretroviral drug use (Yeo et al. 2013).

Monolena primuliflora is referred to as kiru jambi yura by the Payamino people, a name which translates to tooth medicine stem. The stalk of the infructescence (scape) is chewed to relieve toothache. The sourtasting juice is also considered to be a useful thirst quencher. Herbarium records indicate that in the highlands of northern Ecuador the plant is used as an emetic to expel parasites (Rios et al. 2007). Monolena primuliflora is also reported to be used for flu, stomachache, conjunctivitis, and for snakebite (Fierro et al. 2002). To our knowledge the phytochemistry and pharmacology of this species has yet to be explored.

The similarity in the average number of plants identified by males and females provides an interesting insight into the culture and importance of traditional medicine of the Payamino community. Because men and women have different roles in Payamino society, and their roles determine to some extent how they interact with plants, one would expect there to be differences in medicinal plant knowledge between genders (Irvine 1987). The results of our study suggest that Payamino men and women are equally knowledgeable about medicinal plants, a conclusion that is consistent with findings from other studies such as that conducted by Browner and Perdue in San Francisco, Mexico (1988). In contrast, Voeks and Leony (2004) found that women in Bahia, Brazil were much more knowledgeable about medicinal plants and traditional remedies than men. Our results do not support the claim that Payamino women know more about plants that are used in women's health, such as for menstruation or childbirth (Irvine 1987). Of the 25 citations for women's health, 12 were cited by female participants while 13 were cited by males. 
Gender-dependent differences in knowledge of plants used in women's health should be investigated further, however, since we did not include all plants used for women's health in our study. Furthermore, a larger sample size may be necessary to achieve statistical significance.

Since we were unable to demonstrate a difference in medicinal plant knowledge between sexes, it is unclear as to how men and women might manage forest resources differently based on their respective knowledge of medicinal plants. Age, however, has been previously suggested as a predictor of medicinal plant knowledge (Alencar et al. 2014; Ayantunde et al. 2008; Mathez-Stiefel et al. 2012; Quinlan and Quinlan 2007), and younger individuals may not have the same regard for medicinal plants when managing forest resources. On one occasion during our fieldwork, we observed an example of the intergenerational difference in attitudes towards medicinal plants when an elder commented that, against his advice, his son cut down a medicinal plant when clearing forest to plant coffee. In Payamino, Irvine (1987) observed that people older than 40 years of age could identify more forest plants and knew more about their ecology and reproductive biology than did people who were 20 years old or younger. Although some of the youngest informants were surprisingly knowledgeable, our study confirms that older individuals tend to know more about medicinal plants than do younger individuals in Payamino, both in terms of their ability to recognize images of medicinal plants and agreement on their use. The community of San José de Payamino has only gained roadway access to nearby urban centers in the last ten years. While the road may offer more opportunity for education, employment, and sale of agricultural products, it may also have a negative cultural impact on the younger generation with regards to its willingness to learn about the traditional lifestyle of their parents and grandparents. The loss of traditional knowledge has implications for the health of the forest as well as for the health of community members. Plants that are considered to be of value to the community are likely to be preserved along with the habitat in which these plants grow (Berkes et al. 2000). Further work to document medicinal plants of high importance in indigenous communities as well as to determine the distribution of knowledge of these plants among community members might guide education efforts that will positively impact community health and forest ecology.

\section{Conclusion}

The use of digital plant images enabled efficient ethnobotanical data collection in a remote community in the Ecuadorian Amazon. Quantitative analysis revealed that two relatively unstudied plants, $T$. zanonia and M. primuliflora, along with U. baccifera, $C$. lechleri and B. grandiflora, are the most important medicinal plants of those included in the study. There is a positive correlation between knowledge of medicinal plants and age, though there is no difference in knowledge between genders. How distribution of medicinal plant knowledge in Payamino influences the management of forest resources is a topic that should be investigated further.

\section{Acknowledgments}

We would like to express our gratitude to the community of San José de Payamino for their participation in this study and for their hospitality. We would also like to acknowledge the work of Javier Patiño, manager of the Timburi Cocha Research Station, and all of the Alma College students who have contributed in various ways. This study was funded in part by a grant from the McGregor Fund, Detroit, MI.

\section{Declarations}

Permissions: Permission for this study was granted by the IRB of Alma College, the Ministry of Environment of Ecuador, and the Community of San José de Payamino. All participants provided their informed consent.

Sources of Funding: This study was funded in part through a grant from the McGregor Fund, Detroit, MI.

Conflicts of Interest: None declared.

\section{References Cited}

Alencar, N. L., W. S. Ferreira Júnior, and U. P. Albuquerque. 2014. Medicinal Plant Knowledge Richness and Sharing in Northeastern Brazil. Economic Botany 68:371-382. DOI:10.1007/s12231014-9284-5.

Alexiades, M. N. 1996. Collecting Ethnobotanical Data: An Introduction to Basic Concepts and Techniques. In Selected Guidelines for Ethnobotanical Research: A Field Manual, edited by N. M. Alexiades and J. W. Sheldon, pp. 53-94. The New York Botanical Garden Press, Bronx, NY. 
Anderson E., and K. Sax. 1936. A Cytological Monograph of the American Species of Tradescantia. The Botanical Gazette 97:433-476.

Andrade-Cetto, A., and M. Heinrich. 2011. From the Field into the Lab: Useful Approaches to Selecting Species Based on Local Knowledge. Frontiers in Pharmacology 2:1-5. DOI:10.3389/fphar.2011.00020.

Arias, R. I., A. Tapia, A. Tapia, L. Santacruz, R. Yasaca, and N. Miranda. 2012. Evaluación de la biodiversidad en cinco comunidades Kichwa de la zona de colonización de la alsta Amazonía Ecuatoriana. Revista Amazónica: Ciencia y Tecnología 1:157-172.

Ayantunde, A. A., M. Briejer, P. Hiernaux, H. M. J. Udo, and R. Tabo. 2008. Botanical Knowledge and its Differentiation by Age, Gender and Ethnicity in Southwestern Niger. Human Ecology 36:881-889. DOI:10.1007/s10745-008-9200-7.

Bennett, B. C., M. A. Baker, and P. Gomez Andrade. 2002. Ethnobotany of the Shuar of Eastern Ecuador (Advances in Economic Botany Vol. 14). New York Botanical Garden Press, Bronx, NY.

Berkes, F., J. Colding, and C. Folke. 2000. Rediscovery of Traditional Ecological Knowledge as Adaptive Management. Ecological Applications 10:12511262. DOI:10.1890/1051-0761(2000)010 [1251:ROTEKA]2.0.CO;2.

Browner, C. H., and S. T. Perdue. 1988. Women's Secrets: Bases for Reproductive and Social Autonomy in a Mexican Community. American Ethnologist 15:84-97. DOI:10.1525/ae.1988.15.1.02a00060.

Chiriboga, X. 1995. Investigación Fitoquímica de Plantas con Actividad Antibacteriana y Antimicótica. In La Medicina Tradicional en el Ecuador, edited by P. Naranjo and R. Escaleras, pp. 109-116. Universidad Andina Simón Bolívar, Corporación Editora Nacional, Quito, Ecuador.

Colding, J., and C. Folke. 2001. Social Taboos: "Invisible" Systems of Local Resource Management and Biological Conservation. Ecological Applications 11:584-600. DOI:10.1890/1051-0761(2001)011 [0584:STISOL]2.0.CO;2.

Davis, E. W., and J. A. Yost. 1983. The Ethnomedicine of the Waorani of Amazonian Ecuador. Journal of Ethnopharmacology 9:273-297. DOI:10.1016/03788741(83)90036-3.

Doyle, B.J., G.S. Svobodny, R. Batallas, and D. Fernández. 2014. Medical Ethnobotany of the Amazonian Kichwa Community of San José de
Payamino, Ecuador: Preliminary Results from an Undergraduate-Level Field Course. Acta Horticulturae 1030:103-108. DOI:10.17660/

ActaHortic.2014.1030.12.

Fierro, A. F., D. Fernández, and C. Quintana. 2002. Usos de Melastomataceae en el Ecuador. SID A, Contributions to Botany 20:233-260.

Friedman, J., Z. Yaniv, A. Dafni, and D. Palevitch. 1986. A Preliminary Classification of the Healing Potential of Medicinal Plants, Based on a Rational Analysis of an Ethnopharmacological Field Survey among Bedouins in the Negev Desert, Israel. Journal of Ethnopharmacology 16:275-287. DOI:10.1016/03788741(86)90094-2.

Giovannini, P. 2015. Medicinal Plants of the Achuar (Jivaro) of Amazonian Ecuador: Ethnobotanical Survey and Comparison with other Amazonian Pharmacopoeias. Journal of Ethnopharmacology 164:7888. DOI:10.1016/j.jep.2015.01.038.

Gupta, M. P., P. N. Solís, A.I. Calderón, F. GuinneauSinclair, M. Correa, C. Galdames, C. Guerra, A. Espinosa, G. I. Alvenda, G. Robles, and R. Ocampo. 2005. Medical Ethnobotany of the Teribes of Bocas del Toro, Panama. Journal of Ethnopharmacology 96:389-401. DOI:10.1016/j.jep.2004.08.032.

Heinrich, M., A. Ankli, B. Frei, C. Weimann, and O. Sticher. 1998. Medicinal Plants in Mexico: Healers' Consensus and Cultural Importance. Social Science \& Medicine 47:1859-1871.

Hoffman B., and T. Gallaher. 2007. Importance Indices in Ethnobotany. Ethnobotany Research and Applications 5:201-218. DOI:10.1234/era.v5i0.130.

Innerhofer, S., and K. Bernhardt. 2011. Ethnobotanic Garden Design in the Ecuadorian Amazon. Biodiversity Conservation 20:429-439. DOI:10.1007/s10531010-9984-9.

Irvine, D. 1987. Resource Management by the Runa Indians of the Ecuadorian Amazon. Unpublished Doctoral Dissertation, Department of Anthropology, Stanford University, Palo Alto, CA.

Jørgensen, P.M., and S. León-Yánez. 1999. Catalogue of the Vascular Plants of Ecuador. Monographs in Systematic Botany from the Missouri Botanical Garden. 75:i-viii, 1-1182.

Kvist, L.P., M.K. Andersen, M. Hesselsoe, and J.K. Vanclay. 1995. Estimating Use-Values and Relative Importance of Amazonian Flood Plain Trees and 
Forests to Local Inhabitants. Commonwealth Forestry Review 74:293-300.

Licuy-Mamallacta, L. Z. 2013. Estudio Farmacognóstico y Actividad Cicatrizante del Jatun Quilun Quilun. Unpublished Thesis, Escuela Superior Politecnica de Chimborazo, Ecuador.

Martin, G. J. 1995. Ethnobotany: A Methods Manual. Chapman and Hall, London, UK.

Mathez-Stiefel, S., R. Brandt, S. Lachmuth, and S. Rist. 2012. Are the Young Less Knowledgeable? Local Knowledge of Natural Remedies and its Transformation in the Andean Highlands. Human Ecology 40:909-930. DOI:10.1007/s10745-012-95205.

Mootoosamy, A., and M. F. Mahomoodally. 2014. Ethnomedicinal Application of Native Remedies Used Against Diabetes and Related Complications in Mauritius. Journal of Ethnopharmacology 151:413444. DOI:10.1016/j.jep.2013.10.069.

Mutheeswaran, S., P. Pandikumar, M. Chellappandian, and S. Ignacimuthu. 2011. Documentation and Quantitative Analysis of the Local Knowledge on Medicinal Pants among Traditional Siddha Healers in Virudhunagar District of Tamil Nadu, India. Journal of Ethnopharmacology 137:523-533.

DOI:10.1016/j.jep.2011.06.003.

Oldekop, J. A., A. J. Bebbington, K. Hennermann, J. McMorrow, D. A. Springate, B. Torres, N. K. Truelove, N. Tysklind, S. Villamarín, and R. F. Preziosi. 2013. Evaluating the Effects of CommonPool Resource Institutions and Market Forces on Species Richness and Forest Cover in Ecuadorian Indigenous Kichwa Communities. Conservation Letters 6:107-115. DOI:10.1111/j.1755263X.2012.00297.x.

Oldekop, J. A., A. J. Bebbington, N. K. Truelove, G. Holmes, S. Villamarín, and R. F. Preziosi. 2012. Environmental Impacts and Scarcity Perception Influence Local Institutions in Indigenous Amazonian Kichwa Communities. Human Ecology 40:101115. DOI:10.1007/s10745-011-9455-2.

Oldekop, J. A., N. K. Truelove, S. Villamarín, and R. F. Preziosi. 2012. Information Flows in Community -Based Monitoring Exercises in the Ecuadorian Amazon. International Journal of Zoology 2012:4. DOI:10.1155/2012/980520.

Phillips, O., and A. H. Gentry. 1993a. The Useful plants of Tambopata, Peru: I. Statistical Hypotheses
Tests with a New Quantitative Technique. Economic Botany 47:15-32.

Phillips, O., and A. H. Gentry. 1993b. The Useful Plants of Tambopata, Peru: II. Statistical Hypotheses Tests With a New Quantitative Technique. Economic Botany 47:33-43.

Plowman, T. 1977. Brunfelsia in Ethnomedicine. Botanical Museum Leaflets, Harvard University 25:289-320.

Quinlan, M. B., and R. J. Quinlan. 2007. Modernization and Medicinal Plant Knowledge in a Caribbean Horticultural Village. Medical Anthropology Quarterly 21:169-192. DOI:10.1525/maq.2007.21.2.169.

Rios, M., M. J. Koziol, H. B. Pedersen, and G. Granda, eds. 2007. Useful Plants of Ecuador. Applications, Challenges, and Perspectives. Abya-Yala, Quito, Ecuador.

Rossato, S. C., H. F. De Leitão-Filho, and A. Begossi. 1999. Ethnobotany of Caiçaras of the Atlantic Forest Coast (Brazil). Economic Botany 53:387-395.

Sanz-Biset, J., J. Campos-de-la-Cruz, M. A. EpiquiénRivera, and S. Cañigueral. 2009. A first Survey on the Medicinal Plants of the Chazuta Valley (Peruvian Amazon). Journal of Ethnopharmacology 122:333-362. DOI:10.1016/j.jep.2008.12.009.

Savage, J. R. K., and M. A. Pritchard. 1969. Campelia zanonia (L.) H.B.K.: A New Material for the Study of Radiation-Induced Chromosomal Aberrations. Radiation Botany 9:133-134.

Schultes, R. E., and R. F. Raffauf. 1990. The Healing Forest: Medicinal and Toxic Plants of the Northwest Amazonia. Dioscorides Press, Portland, OR.

Tardío J., and M. Pardo-de-Santayana. 2008. Cultural Importance Indices: A Comparative Analysis Based on the Useful Wild Plants of Southern Cantabria (Northern Spain). Economic Botany 62:24-39. DOI:10.1007/s12231-007-9004-5.

Tene, V., O. Malagón, P. V. Finzi, G. Vidari, C. Armijos, and T. Zaragoza. 2007. An Ethnobotanical Survey of Medicinal Plants Used in Loja and Zamora-Chinchipe, Ecuador. Journal of Ethnopharmacology 111:63-81. DOI:10.1016/j.jep.2006.10.032.

The Plant List. 2013. Version 1.1. Available at: http:// www.theplantlist.org. Accessed on November 16, 2016.

Thomas, E., I. Vandebroek, and P. Van Damme. 2007. What Works in the Field? A Comparison of Different Interviewing Methods in Ethnobotany 
with Special Reference to the Use of Photographs. Economic Botany 61:376-384. DOI:10.1663/0013-0001 (2007)61[376:WWITFA]2.0.CO;2.

Timburi Cocha. 2015. Map provided by the Timburi Cocha Research Station, San José de Payamino, Orellana, Ecuador.

Trotter, R. T., and M. H. Logan. 1986. Informant Consensus: A New Approach for Identifying Potentially Effective Medicinal Plants. In Plants in Indigenous Medicine and Diet: Biobehavioral Approaches, edited by N. L. Etkin, pp. 91-112, Redgrave Publishing Company, New York, NY.

Vandebroek, I. 2010. The Dual Intracultural and Intercultural Relationship between Medicinal Plant Knowledge and Consensus. Economic Botany 64:303317. DOI:10.1007/s12231-010-9135-y.
Voeks, R. A., and A. Leony. 2004. Forgetting the Forest: Assessing Medicinal Plant Erosion in Eastern Brazil. Economic Botany 58:S294-S306. DOI:10.1663/0013-0001(2004)58[S294:FTFAMP] 2.0.CO;2.

Whitecloud, S. S., and L. A. Grenoble. 2014. An Interdisciplinary Approach to Documenting Knowledge: Plants and Their Uses in Southern Greenland. Arctic 67:57-70.

Yeo, Q. M., R. Crutchley, J. Cottreau, A. Tucker, and K. W. Garey. 2013. Crofelemer, a Novel Antisecretory Agent Approved for the Treatment of HIVAssociated Diarrhea. Drugs of Today 49:239-252. DOI:10.1358/dot.2013.49.4.1947253. 